\title{
Returning to School: Separation Problems and Anxiety in the Age of Pandemics
}

\author{
Martha Pelaez ${ }^{1}$ (D) Gary Novak ${ }^{2}$ \\ Published online: 15 July 2020 \\ (C) Association for Behavior Analysis International 2020
}

\begin{abstract}
The shift to the postpandemic school environment will cause dramatic changes and is likely to increase separation problems. In this article, we look at the anxiety problems that some parents and their children might experience when school reopens after the COVID-19 lockdown. Using a behavioral theory of development, we provide suggestions for how to handle the departure and separation problems that may emerge as parents drop their children off at school. Many parents are unsure about how to handle anxiety or fear as their children return to school or have to visit other environments outside their homes. Social distancing has caused families to develop stronger dependencies at home and to create new routines that vary, in many instances greatly, from their prepandemic routines. Families are adjusting to the new "normal." They are keeping their children busy with schoolwork as best they can. In particular, families have likely developed close attachment relationships. Families have been struggling with an unprecedented lockdown, and for many parents and their children, this extended period of family confinement and severe restrictions has been especially stressful, and the timing for returning to school is uncertain. We emphasize here that parents can be responsive to their children's needs, plan ahead, provide reassurance, and depart firmly without vacillating, and we provide other tips to avoid inadvertently shaping children's negative or anxiety behaviors as they go back to school. We offer some specific advice for parents and teachers to follow to prevent the departure and separation problems that typically develop during challenging behavioral interactions in school settings.
\end{abstract}

Keywords Postpandemic schools $\cdot$ School after COVID-19 $\cdot$ Separation protests and anxiety

The COVID-19 virus invasion and its impact on human behavior have been quick and unprecedented. It has abruptly produced a series of significant challenges and opportunities for those who study human behavior. In this article, we look at some special implications for understanding its impact on children and how we care for them. We also look

Editor's Note This manuscript is being published as part of a series of emergency publications designed to help practitioners of applied behavior analysis take immediate action to adjust to and mitigate the COVID-19 crisis. This article was submitted on April 20, 2020, and received final acceptance on May 20,2020. The views and strategies suggested by the articles in this series do not represent the positions of the Association for Behavior Analysis International or Springer Nature.

Martha Pelaez

Martha.Pelaez@ fiu.edu

1 College of Arts, Sciences, \& Education, Florida International University, Miami, FL, USA

2 California State University, Stanislaus, Turlock, CA, USA specifically at one aspect of this situation: departure and separation protests in young children (although older children, adolescents, and parents themselves may also experience separation issues). We view separation anxiety from the perspective of behavioral developmental theory. Further, we make suggestions for how to deal with the young child's protests after requirements for social distancing are over. Many parents are unsure about how to handle their children's anxiety or fear as their children return to school or have to visit other environments outside their homes. Social distancing has caused families to develop strict home routines as they have been struggling with an unprecedented lockdown. For many parents and their children, this extended period of family confinement and severe restrictions has been especially stressful. But some families have adapted by creating constructive routines and learning environments for their children, maintaining a positive attitude, and trying to balance work at home with family time. Others have fallen into more problematic patterns of behavior, such as coercive interactions. 
In this article, we stay focused on the separation situation and its effects on parents and young children by using the lens of behavioral development theory (Novak \& Pelaez, 2004). Our treatment of separation protests is uniquely based on behavior-analytic research (Gewirtz \& Pelaez-Nogueras, 1990, 1991, 1992). We conclude by offering specific suggestions about how to handle the separation difficulties that will inevitably emerge in some families upon returning to school.

\section{Families and Schools as Behavioral Systems}

The COVID-19 crisis came on quickly in the US winter and in the spring of 2020, right in the middle of the school year. One of the immediate effects was the sudden disruption of the dynamic interactions among children and their care providers. In many communities, total social distancing was invoked with little warning. Existing relations with teachers and peers were completely shut down, and families were left to scramble to find new ways to care for and educate their children as a replacement.

Our behavioral systems theory (BST; Novak, 1996, 1998; Novak \& Pelaez, 2004) incorporates developmental dynamicsystems concepts into behavior analysis. BST treats both schools and families as behavioral systems. In the case of schools, the ongoing reciprocal interactions among children and teachers and peers in the classroom develop into functioning systems that are highly efficient in producing reinforcers (both positive and negative). The same is true for the behavioral systems that children participate in at home with parents, grandparents, and siblings. These dynamic transactions take time to develop but become well attuned to the contingencies over time. A sudden and drastic change of conditions, as that which has occurred with the shutdown of schools in response to the COVID-19 outbreak, means these well-adapted behavioral systems are thrown into chaos. That means many previously reinforced behaviors are no longer reinforced, establishing operations are no longer in effect, and once available cues for guiding the child (and parents) are now missing. Consequently, the two systems have been disrupted quite decidedly.

One way to look at the impact on behavioral development is to look at the disruptions they produce in all four terms of the behavioral contingency chain. In most U.S. households, time spent in school or preschool is a significant part of a child's everyday life. Typical patterns of interaction emerged in the hours the child spent transacting with teachers and fellow peers. Some of these interactions are primarily academic in nature, and nearly all of them involve social interactions. Likewise, parents spent a significant part of the day at work, where they develop social interactions with coworkers and perhaps the public. In both the school and work environmental systems, participants develop strongly reinforced patterns of interactions based on behavioral contingencies and social rules. The new social-distancing rules in this age of pandemic have eliminated some of these former contingencies and created fresh ones.

The conditions produced by the COVID-19 pandemic serve as establishing operations or motivating operations for the development of attachment problems such as separation protest and anxiety. That is, the pandemic presents environmental variables that alter the effectiveness of stimuli, objects, or events as a reinforcer. Among these possible motivational or setting conditions are the hospitalization of a parent or other family member, the unfortunate death of a parent or other family member, the worrisome TV news about the virus, the reports on job losses and a bad economy, and the negative reactions of others to the news. Fear and anxiety can increase by watching continual updates on the COVID-19 pandemic, and information directed at adults can cause anxiety and confusion, particularly in young children.

All these experiences work to increase the general anxiety and fear of separation, leaving home and returning to school, and returning to a school environment that parents consider still unpredictable and uncontrollable. We offer some recommendations to parents on how to work with schools and teachers to cope with some of these emerging problems.

\section{Parent as Teacher: Stressors}

Although parent-child interactions were a part of wellestablished previrus family systems before and after school, with social-distancing policies, online virtual interactions have become nearly the sole source of social interactions outside the family. Parental roles have also changed. No longer is the parent's role to support the child's learning in school. Now, parents are the school. No longer do parents have to supervise their children for only a few hours before and after school. Now they have daylong supervision responsibility. Also, in cases where both parents are still working in essential jobs, stress is added to the situation by the need to secure childcare or education, with schools closed for half of the 2019-2020 school year and possibly the 2020-2021. Furthermore, the pandemic has placed additional stress on families by eliciting fear of contracting the illness and producing job and huge economic losses.

We predict that one initial effect of the changes the pandemic has triggered is increased variability in behaviors of individuals in the family and school systems. Largely, this variability occurs when formerly reinforced patterns of behavior are no longer reinforced because old system participants (e.g., teachers and peers) are no longer present. Because of physical-distancing rules, for example, a friend's touch or hug may no longer be available to reinforce as it had in the past. 
Thus, increased emotional withdrawal and frustration are also likely to result from withholding some reinforcers (i.e., extinction), which in turn further fuels response intensity and even more variability. Together, these withdrawing conditions and the loss of reinforcement may evoke bursts of novel child responses that produce parental reinforcement during coercive interactions. Put simply, the child may start acting out in exaggerated ways to obtain reinforcement (e.g., proximity, attention). Unfortunately, we have evidence that many of these aversive child responses can be shaped by inadvertent parental responses that wind up strengthening undesirable child-parent behavioral interactions through negative reinforcement traps, as detailed in Patterson's coercive family process (Patterson, DeBaryshe, \& Ramsey, 1989).

\section{Separation Protests in Returning to School}

One of the hardest decisions parents are making is determining when is the right time for their children to return to the classroom (summer or fall). The postpandemic situation is unique due to its length. The family interactional systems that have been reorganized and will newly emerge will have had a far longer time for patterns to be established. The scope of daily interactions is much broader than summer break and encompasses new educational responsibilities in addition to supervisorial and recreational ones. Attachment and dependency are likely to be even stronger than the previous norm. Therefore, what we are likely to see is another significant move of virus disruption in a highly efficient family system in which both parents and children are strongly attached and will have more difficulty adapting to the "new normal" systems in a postvirus era in schools. In the remainder of this article, we will utilize a behavioral systems approach to address this important issue, as we anticipate increasing problems when children return to their school environments. We will describe some of the research on the variables leading to separation protests and suggest actions that may reduce the number and intensity of these.

\section{The Child's Separation Protests and Attachment}

Parents' behaviors are likely to reinforce their children's proximity, attention, and affection. When the child's proximityand security-regulating behaviors become organized around a parent or caregiver, we say the child has developed an attachment (Bretherton, 1987, p. 1063). By "organized," we mean that more than just individual responses occur. Child attachment is characterized by dynamic patterns of behaviors reinforced by proximity to the parent or main caregiver. Parents' behaviors, too, are reinforced by proximity to their children, and parents may become "attached" to them. Thus, behavioral systems are bidirectional and reciprocal. Parents are also liable to have heightened feelings of attachment and, if severe, may need additional help to treat behaviors characteristic of separation anxiety disorder that are described in the Diagnostic and Statistical Manual of Mental Disorders (American Psychiatric Association, 2013).

However, the focus of this article is on the prevention and compassionate management of young children's separation protests in returning to school. Visit nearly any childcare center or preschool at the beginning of a new academic year and you are certain to observe young children's separation protests. These young children's protests typically take the form of whining, crying, throwing tantrums, clinging to the parent when leaving, and refusing to detach. Separation protests are commonly used to measure security or insecurity of attachment (Ainsworth, Blehar, Waters, \& Wall, 1978) and separation anxiety (Kagan, Kearsley, \& Zelazo, 1978). We have emphasized that there is a possibility that the child's separation protest might develop as learned responses during interactions with primary caregivers (Gewirtz \& Pelaez-Nogueras, 1990, 1991, 1992).

Gewirtz and Pelaez-Nogueras (1990, 1991, 1992) conducted several intervention studies on how mother-infant interactions influence the development of separation protests and distress. They applied the results of those studies to provide guidance to parents. In light of the COVID-19 crisis, when children return to school and separate from their parents after a months-long period of 24-hr-a-day interaction that occurred during a period of social distancing, we predict that high rates of protest and distress may emerge, as well as high rates of refusal to leave the parents. This is likely to produce heightened child separation-protest responses that can disrupt classroom settings the new physical distancing rules, and provoke anguish and anxiety in parents. Thus, the way that the departures and separations are handled by parents and teachers may have positive or negative consequences for all - children, parents, and school settings.

\section{The Conditioning of Separation Protest and Anxiety}

Researchers have shown that contingent maternal responding to separation protests can shape children's behaviors, such as whining, crying, and throwing tantrums (Gewirtz \& PelaezNogueras, 1991). They have further shown that separation protests could be reduced if parents differentially reinforced behaviors other than protest behaviors, such as playing with toys. Although the research demonstrates how the family is a system, and although the caregiver is likely to shape the child's behavior in separation protests, the interactions have reciprocal effects. That is, although mothers and teachers can 
"inadvertently" reinforce the child's separation protest, the caregiver's behavior is likely to be negatively reinforced by reducing or stopping (at least in the short run) the child's crying/protesting and anxious behavior. Specifically, the caregiver's attachment behavior can be shaped by terminating or escaping the aversiveness of his or her child's separation protest; simultaneously, the child's protest behavior is being shaped by the contingencies (e.g., touching, hugging, vacillating, talking, and overreassuring the child) provided by the parent returning to the protesting child in the classroom.

\section{Some Advice for Parents on How to Separate Without Tears or Anxiety}

Few parents know how to cope with the crying and tantrums of their children, especially in situations in which they are getting ready to leave their children at school for the first time or when they will return to school during or after the pandemic. This lack of knowledge is completely normal. At the beginning of school, children's protests and cries can delay their parents' departures and cause them to return to school after dropping their children off. The research we discussed earlier shows that, during departures and at separation, parents' responses to children's protests can encourage and reinforce more of this distressing behavior. Even more problematic is that when parents intermittently reinforce protests, these protests may escalate and get worse. In this section, we offer some advice for parents to follow to prevent maladaptive behavior interactions.

The behavior-analytic view is that parental responses in this situation can encourage and otherwise shape the child's behavior patterns. Unfortunately, our responses as parents often make it more difficult for our children to separate in the long term. We often inadvertently provide "misplaced contingencies" under such commendable intentions as providing a secure base or loving attention to our children and their needs. Let us provide observations of what happens when a parent provides the "goodbye cues."

\section{The Goodbye Cues}

A child's separation protests are routinely cued by a parent's preparations to leave the child in school or other settings. The behavioral cues that signal parental departure and separation can involve a mother picking up her car keys and purse, placing her baby in the crib or playpen while saying goodbye, or the arrival of a babysitter or caregiver. These cues serve as discriminative stimuli for child protests, as well as stimuli that evoke emotional distress in both child and parent. A parent may fear that the young child may not be safe in the school in this era of COVID-19. In older children, the cues would differ, and the parents may reason and provide explanations and a series of new instructions to the child. These new physical distancing rules may disrupt the existing family routine. We described this earlier as disruption and chaos in the dynamic system.

Departure-cued protests can include fusses, whines, whimpers, cries, and screams. In children with more advanced verbal and motor skills, protests may also involve grabbing the parent's body or clothes, clinging, pleading, or throwing a loud temper tantrum and refusal to leave the parent. These behaviors often cut short a separation from the parent. They also may further increase the emotional upset in the home setting. The parent's anguished responses to the child's protests can include delaying a departure, returning to hug the child, engaging in extensive reasoning with the child, vacillating during the departure, or hesitating to separate. The parent's anxious behavior may also include returning to school to pick up the child after having left the classroom in response to the teacher's call about a child's protest. Often, parents return to touch, pick up, or hug and kiss the protesting child. These well-intended parental behaviors provide attention contingent on the child's protests, therefore strengthening them. In turn, during the transaction the child simultaneously trains the parent to behave this way, by stopping the protests contingent on the parent delaying departures, cutting short separations, or taking the child back home. Thus, parents' behavior problems and anxiety responses can result from children's responses during the transactions. The serious situation of COVID-19 virus transmission exacerbates all these scenarios, mainly because all the establishing operations or setting conditions it produces increase fear and anxiety of separation and the child getting infected.

\section{Recommendations for Parents, Behavior Analysts, and Teachers}

We discussed that parents' and teachers' attending reactions to infant protests during departures and after separations actually make recurrences of protests more likely in future situations. We also emphasized that intermittent reinforcement of protests will likely make them more resistant to extinction. The child's response bursts and variability are more likely to occur. Parents with separation anxiety may have more fears and may want to check more frequently on their children. These parents may demand to know where their children are at all times by texting, making the teacher's job very difficult. In general, parents may have difficulties with separation from their children at all times, most specifically in light of the virus's risks of infection.

To minimize separation distress, parents could program with teachers controlled visits to the child's classroom when the child has not recently protested and has remained there 
for varyingly longer periods. On each of these occasions, after parents drop off the child at school or classroom, the situation would be less stressful if the parent departs from the setting in a straightforward manner and is reassured by school personnel that the situation is under control. At the beginning of the separation episode, the classroom teacher in charge should provide reassurance to children that their parents will come back to pick them up at the end of the day. The new classroom routines and rules during and after the COVID-19 pandemic should be established clearly and discussed ahead of time with parents and their children before they come back to school. Some of the preliminary training can occur via virtual technology like Zoom or telehealth techniques showing the new classroom arrangements and rules (e.g., handwashing routines, wearing face covers, physical distancing). It is important to keep in mind that parents and teachers should contact a professional if any child exhibits significant changes in behavior that suggest something else is amiss with the child that requires intervention from a child psychologist.

\section{Steps for Parent-Child Separations When Returning to School}

Going back to school after a prolonged and intense period locked down at home will require many adaptations to new environments, of which school is only one. In order to facilitate the shift from home to school, we offer several recommendations that parents can use to make parting less painful and anxious for their children.

Learn the new rules and routines of the classroom, and plan ahead. Develop a plan for dealing with separation and new classroom routines and rules. Involve the teacher's rules and plans in your own planning. Discuss these with your child ahead of time. As a parent, you could write a description of your strategy for responding to your child's protests, e-mail it to the teacher, and invite the teacher to give input about how it fits into the classroom setting and how he or she may help you. At a minimum, this will keep the teacher informed of your intentions and concerns.

Listen carefully to the child. Children give off verbal and nonverbal cues about their anxiety level. This will alert you to the likelihood of problems and may allow you to be especially reassuring and prepared for them. For younger children, while at home and talking to your child about returning to school, you might ask your child to make a drawing about his or her thoughts or concerns, and respond with truth and reassurance.
Model calm. Be calm and relaxed. Anticipate child protests and plan how to react calmly. Model calm behavior during difficult situations, and "catch" your child being calm and richly reinforce it (see resources).

Create a less stressful environment. Before your departure, ensure that your child is safe, relaxed, and positively engaged in an activity. Use this to establish the conditions for a less stressful and safe departure. Have the teacher greet your child in a warm and welcoming manner. Check with the teacher about quickly providing a positive routine, such as helping prepare a snack or playing with a good friend.

Announce your departure. As soon as possible, follows physical distancing rules after arriving at the classroom, you should make sure the child follows physical distancing rules is welcomed into an activity (e.g., playing) and announce your departure to your child in a straightforward manner (e.g., by saying, "I'll be back for you later. I love you.").

Make the explanation clear and short. For younger children, you could simply say, "Mommy has to go now, but I'll be back soon. Have fun," give a kiss, and leave. For older children, you might also explain the departure ahead of time and indicate when you plan to return. Reassure children that they are okay. However, once at school, such an explanation should be very short. Do not negotiate. Do not respond to protests with additional explanation or negotiation. Negotiating runs the risk of reinforcing the child's protests. Instead, focus on the positive. Follow your plan, and leave without hesitating.

Depart without vacillating. You should leave the setting directly without hesitation. There is no need to appear rushed, but hesitating will only give the wrong cues and make it more difficult for you and your child.

Do not return. Once you have left, you should not come back to pick up or talk to a protesting child. Remember, occasional reinforcement of some protests will likely make the protests worse and make it harder for your child in the long term.

Behave consistently. Have a routine that you continue to follow despite any protests. This predictability will make it easier for your child to learn that everything is normal. This will help your child integrate into the new daily postpandemic classroom routine. Inconsistent experiences are likely only to produce more emotional upset and intermittently reinforce undesired behaviors.

We would like to close our recommendations with a quote from the National Association of School Psychologists website: 
It is very important to remember that children look to adults for guidance on how to react to stressful events. Acknowledging some level of concern, without panicking, is appropriate and can result in taking the necessary actions that reduce the risk of illness. Teaching children positive preventive measures, talking with them about their fears, and giving them a sense of some control over their risk of infection can help reduce anxiety. This is also a tremendous opportunity for adults to model for children problem-solving, flexibility, and compassion as we all work through adjusting daily schedules, balancing work and other activities, getting creative about how we spend time, processing new information from authorities, and connecting and supporting friends and family members in new ways (NASP, 2020).

Funding information The present study was not funded by any relevant grants or other funding sources.

\section{Compliance with Ethical Standards}

Conflict of Interest The authors declare that no relevant conflicts of interest influenced the nature of the present research investigation.

Ethical Approval All procedures performed in studies involving human participants that participated in the studies cited that were conducted by Pelaez et al. were in accordance with the ethical standards of the institutional and/or national research committee and with the 1964 Helsinki declaration and its later amendments or comparable ethical standards.

Informed Consent This is a brief report, and no data were collected. Informed consent in the studies cited in this article (by Gewirtz \& Pelaez-Nogueras, 1990, 1991, 1992, 1993.) was obtained from the parents of the infants who participated in those studies. Specifically, if the parent's child met the characteristics for participation in the study and the parent provided consent-for-participation forms for both him- or herself and his or her child (via parental and child consent forms), the child would then begin the assessment procedures. The primary investigator was available and willing to answer any questions that the parent may have had regarding the study and his or her child's participation throughout every session. Further, the consent form stressed that the parent may withdraw his or her child's participation at any time and that all participation was purely voluntary in nature.

\section{Resources}

- Coping With Stress During Infectious Disease Outbreaks: https://store.samhsa.gov/product/Coping-with-Stress-DuringInfectious-Disease-Outbreaks/sma14-4885
- Centers for Disease Control and Prevention, Coronavirus Disease 2019 (COVID-19): https://www.cdc.gov/ coronavirus/2019-ncov/prepare/children.html

NASP COVID-19 Resource Center: https://www. nasponline.org/COVID-19

\section{References}

Ainsworth, M. S., Blehar, M. C.,Waters, E., \&Wall, S. (1978). Diagnostic and statistical manual of mental disorder, (5th Ed.) Arlington, VA: American Psychiatric Association.

Ainsworth, M. S., Blehar, M. C., Waters, E., \& Wall, S. (1978). Patterns of attachment. Hillsdale, NJ: Erlbaum.

Bretherton, I. (1987). New perspectives on attachment relations: Security, communication, and internal working models. In J. D. Osofsky (Ed.), Handbook of infant development (2nd ed., pp. 1061-1100). New York, NY: John Wiley.

Gewirtz, J. L., \& Pelaez-Nogueras, M. (1990). Social-conditioning theory applied to metaphors like "attachment": The conditioning of infant separation protests by mothers. Mexican Journal of Behavior Analysis, 13, 87-103.

Gewirtz, J. L., \& Pelaez-Nogueras, M. (1991). The attachment metaphor and the conditioning of infant separation protests. In J. L. Gewirtz \& W. M. Kurtines (Eds.), Intersections with attachment (pp. 123-144). Hillsdale, NJ: Erlbaum.

Gewirtz, J. L., \& Pelaez-Nogueras, M. (1992). Infants' separation difficulties and distress due to misplaced maternal contingencies. In T. Field, P. McCabe, \& N. Schneiderman (Eds.), Stress and coping in infancy and childhood (pp. 19-46). Hillsdale, NJ: Erlbaum.

Gewirtz, J. L., \& Pelaez-Nogueras, M. (1993). Leaving without tears: Parents inadvertently train their children to protest separation. Child and Adolescent Behavior, 9, 1-4. The Brown University Press.

Kagan, J., Kearsley, R. B., \& Zelazo, P. R. (1978). Infancy: Its place in human development. Cambridge, MA: Cambridge University Press.

National Association of School Psychologists. (2020). Helping children cope with changes resulting from COVID-19. Retrieved June 18, 2020 from: https://www.nasponline.org/resources-andpublications/ resources-and-podcasts/school-climate-safety-and-crisis/healthcrisis-resources/helping-children-cope-with-changes-resultingfrom-covid-19

Novak, G. (1996). Developmental psychology: Dynamical systems and behavior analysis. Reno, NV: Context Press.

Novak, G. D. (1998). Behavioral systems theory. Mexican Journal of Behavior Analysis, 24, 100-112.

Novak, G., \& Pelaez, M. (2004). Child and adolescent development: A behavioral systems approach. Thousand Oaks, CA: Sage Publications.

Patterson, G. R., DeBaryshe, B. D., \& Ramsey, E. (1989). A developmental perspective on antisocial behavior. American Psychologist, 44(2), 329-335.

Publisher's Note Springer Nature remains neutral with regard to jurisdictional claims in published maps and institutional affiliations. 